\title{
Veterinarians' Perception, Knowledge and Practices of Antibiotic Stewardship in Enugu State Southeast, Nigeria
}

\author{
Madubuike Umunna ANYANWU ${ }^{1 *}$, Oluwatosin Ajoke KOLADE ${ }^{2}$ \\ ${ }^{1}$ University of Nigeria, Microbiology Unit, Department of Veterinary Pathology and Microbiology, \\ Nsukka; madubuike.anyanwu@unn.edu.ng ('correspondingauthor) \\ ${ }^{2}$ University of Nigeria, Veterinary Teaching Hospital, Nsukka; oluwatosin.kolade@unn.edu.ng
}

\begin{abstract}
A cross-sectional survey utilizing structured questionnaires was used to study the veterinarians' perception, knowledge and practices of antibiotic stewardship (ABS) in Enugu State, Southeastern Nigeria. Data obtained were analyzed using chi-square on SPSS (Version 15.0) at a significance level of $P<0.05$ to determine possible associations between variables and perceptions/knowledge about ABS. Out of 280 respondents, 41 (17.1\%) had heard about ABS. Minority of the respondents perceived/knew that using antibiotics only when necessary $(6.4 \%, 18)$, administering antibiotics at the appropriate dose $(6.4 \%$, $18)$ and administering antibiotics for appropriate duration in every case $(4.3 \%, 12)$ were among the principles of ABS. The study also showed that age, gender, qualification, years of practice and locations did not exert any influence $(P>0.05)$ on the awareness of respondents about ABS. More than one-third of the respondents wrongly perceived that increasing the use of broad-spectrum antibiotics $(35.4 \%, 99)$ is one of the goals of ABS, whereas the minority of the respondents rightly perceived/knew that minimizing toxicity and other adverse effects $(16.8 \%, 47)$ and reducing antibiotic resistance (ABR) $(43.2 \%, 121)$ are also goals of ABS. Only $21.4 \%(60)$ had overall knowledge of ABS. Prescribing antibiotics without seeing/examining the patient, prescribing antibiotics for any case suspected to be infectious, prescribing broad-spectrum antibiotics despite availability of narrow-spectrum antibiotics, prescribing different classes/types of antibiotics concurrently to ensure therapeutic efficacy, prescribing overdose of antibiotics to ensure efficacy and non-consultation of the veterinary formulary/other resources when in doubt during prescription, are some of inappropriate/untoward ABS practices/behaviors/attitudes amongst the respondents. No significant association $(P>0.05)$ was found between practices of $A B S$ and age, gender, qualification, years of practice and location. In conclusion, the veterinarians' awareness/perception and practices of $A B S$ is abysmally poor in the study area, thus education of Nigerian veterinarians about ABS and the teaching of the principles and practices of $\mathrm{ABS}$ during veterinary schools are recommended.
\end{abstract}

Keywords: antibiotic resistance, antibiotic stewardship, veterinarians, knowledge, practices

\section{Introduction}

The threat posed by antibiotic resistance (ABR) has recently been equated to climatic change and it is of grave concern globally (Castro-Sanchez et al., 2016). The health (substantial morbidity and mortality) and economic impact of ABR on a global scale is enormous and dreadful (Cosgrove, 2006; Castro-Sanchez et al., 2016). In European Union, the overall societal costs of $A B R$ and complications arising from $\mathrm{ABR}$ were estimated to be $€ 1.5-9$ billion per year (Llor and Bjerrum, 2014; Cisneros et al., 2014) and an estimated mortality of 25,000 people annually (WHO, 2012; Scaioli et al., 2015). In United States, around 26,000 people die of multidrug-resistant bacterial infections each year (Spellberg et al., 2008; Khan et al., 2016), while 96,000 deaths are attributed to multidrug resistance in Southern Asia (Zaidi et al., 2004; Khan et al., 2016). Worldwide, it has been underestimated that about 700,000 lives are lost annually due to antimicrobial-resistant infections (O'Neil, 2014). It is also estimated that by 2050 , the societal and financial cost of not tackling the ABR crisis will be US $\$ 100$ trillion (O'Neil, 2014; Piddok, 2016). Some studies estimated population reduction of between 11 million and 444 million people and a reduction in the size of the global economy by $0.1-3.1 \%$ by 2050 if effective antimicrobial agents are not developed (Taylor et al., 2014; Fitchet and Attun, 2016). The cost of developing a new antibiotic has been estimated to be US $\$ 1$ billion (Huttner et al., 2013), but no new antibiotic is expected to be on the market until 2018 at the earliest (Bartlett, 2011; Cisneros et al., 2014). 
322

Very recent, it was reported that new antibiotics are expected to be in the market earliest in 2022 (Leonard et al., 2017). It was also estimated that US $\$ 30$ billion are needed to tackle $\mathrm{ABR}$ crisis now, before it becomes uncontainable (O’Neil, 2014; Piddok, 2016). In developing nations, including Nigeria, the impact of $\mathrm{ABR}$ is worse, and unfortunately, the cost of treatment of resistant infections and associated deaths are unaccounted for (Huyhn et al., 2015).

The contributions to $A B R$ are multidimensional and range from behavioural dynamics of healthcare workers (including veterinarians) and to the biology of the microorganisms (Levy, 2002; Castro-Sanchez et al., 2016). The most common cause of ABR is inappropriate use (Paul and Gyssens, 2013; Cotta et al., 2014). Antibiotics are the most frequently prescribed drugs, but they are often misused (Chambers, 2006; WHO, 2014; Scaioli et al., 2015). Wrong prescribing behavior amongst clinicians has been linked as a major cause of antibiotic misuse (Scaioli $e t$ al., 2015). Inappropriate use of antibiotics is widespread in human/veterinary hospitals, especially in developing countries, including Nigeria, and up to $50 \%$ of antibiotic treatments prescribed have been estimated to be incorrect (Dellit et al., 2007; Pulicini and Gyssens, 2013; Cisneros et al., 2014). All clinicians (including veterinarians) are potential antibiotic prescribers; therefore, the generalization of antibiotic misuse is probably due to a misbalance between the high level of knowledge required for the appropriate use of antibiotics and the scarce training offered in this respect to the practicing clinician (Cisneros et al., 2014; Awad and Aboud, 2015).

Clients/patients' wrong habits and their lack of knowledge has also been reported as a leading cause for ABR (Grigoryan et al., 2007; Scaioli et al., 2015).

Because factors that triggers ABR is multidimensional, multimodal/multifaceted interventions have been suggested to be of most benefit (Awad and Aboud, 2015; CastroSanchez et al., 2016). Such interventions are aimed at strengthening the concept of One Health at the humananimal-environment interface because antibiotic-resistant organisms easily pass from one environment to the other and vice versa (WHO, 2014; Cabello et al., 2016; Kock et al., 2016). It is established that containment of ABR could only be possible if containment strategies are employed in all healthcare environments (Abbo et al., 2013). Antibiotic stewardship is an integrated and multidisciplinary approach that includes the selection of appropriate antibiotic, enhanced surveillance of prescribing and use, implementation of prescribing guidelines and policies, inclusion of infection prevention and control strategies, and increased efforts on audit and education (Cisneros $e t$ al., 2014; Roca et al., 2015). The development of antibiotic stewardship programmes (ASPs) in the hospital/veterinary setting has been encouraged by scientific societies worldwide (Dellit et al., 2007; Srinivasan, 2011; Cisneros $e t$ al., 2014; Bowater, 2015), and they have proved to be an essential measure in controlling the rise of $A B R$ and antibiotic expenditures (Moody et al., 2012; Cisneros et al., 2014; File et al., 2014).

Collaboration of all healthcare providers (involved in antibiotic use) is critical for ASPs to be successfully implemented (Cotta et al., 2014; Viale et al., 2015; Cabello et al., 2016). Thus, veterinarians (as clinicians and educators) play a critical role in $\mathrm{ABS}$ and for successful implementation of ASP (Bowater, 2015; Coyne et al., 2016). Antibiotics used in humans, including the critically important ones, are in the same classes as those used in animals (WHO, 2011; Landers et al., 2012; Awad and Aboud, 2015). Emergence of resistant infections in animal populations can impact health and productivity, and potentially transfer to humans (zoonosis) (van Djuikeren $e t$ al., 2014; Coyne et al., 2016). But for veterinarians to implement and help in achieving the goals of ABS, they (as healthcare providers/professionals), should be interested in and knowledgeable about ABR and ABS (Awad and Aboud, 2015; Guardabassi and Prescott, 2015; Coyne et al., 2016). Knowledge about ABS is critical for veterinarians because they are anticipated (as key healthcare providers) to take prominent roles in infection control programmes in healthcare (veterinary) systems and as educators of their clients/the public about ABR and ABS (Bowater, 2015; Khan et al., 2016). Therefore, assessing the veterinarians' perception and level of knowledge/awareness about ABS is crucial for identifying gaps in knowledge, development of effective ASPs and improvement of the curricula in Veterinary schools (Abbo et al., 2013; Paul and Gyssens, 2013; Cotta et al., 2014; Coyne et al., 2016). Moreover, taking into account the potential role of veterinarians in the development and execution of ASPs, it is imperative to know the practices/behaviours/attitudes of veterinarians towards ABS (Coyne et al., 2016). This is crucial in order to understand the level of engagement among veterinarians as clinical stakeholders involved in antibiotics prescription and dispensing, determine key areas that will be useful in developing ASP and for education of the veterinarians/public which is an integral part of all $A B R$ containment activities (Vickers, 2011; Abbo et al., 2013; Cotta et al., 2014).

However, while there are several reports on perception/understanding and practices of $\mathrm{ABS}$ among several key healthcare providers (such as pharmacists and doctors) in many parts of the world, there is paucity of information (Busani et al., 2004; Cattaneo et al., 2009; Coyne et al., 2016) regarding the perception/level of awareness and practices of $A B S$ among veterinarians in available literature. In Nigeria, Veterinary Medicine is a 6 years full-time University degree programme, courses on antibiotics and ABR are taught in the $3^{\text {rd }}$ and $4^{\text {th }}$ years. In the final year $\left(6^{\text {th }}\right.$ year $)$, students are also engaged in clinical postings during which they are further exposed to antibiotic sensitivity testing and drug prescriptions in the Veterinary Teaching Hospital. Thus, every Nigerian veterinarian is expected to have basic knowledge of ABR A 1-year postgraduation national youth service, during which a fresh Doctor of Veterinary Medicine (DVM) graduate is expected to start prescribing drugs, is often compulsory for every veterinarian in Nigeria. Although, there are Postgraduate degrees/Diploma programmes (such as Masters, Doctorate, etc), many Nigerian veterinarians may not be knowledgeable about $\mathrm{ABS}$, and therefore, may be 
prescribing/using antibiotics injudiciously. This sort of practice increases the problem of ABR in the country. Till date, no study has evaluated the Nigerian veterinarians' understanding of the concept and practices of ABS. This study was therefore undertaken to assess the perception/level of knowledge and practices of ABS amongst veterinarians in Enugu State, Southeast Nigeria. The data will help in identifying gaps in knowledge and to understand veterinarians' perceptions that could help in implementation of appropriate remedies in Nigerian Veterinary Schools' curricula that will subsequently affect behavioural change and lead to more appropriate use of antibiotics.

\section{Materials and Methods}

\section{Study area and population}

The study was carried out in Enugu State, Southeastern Nigeria between January and March, 2017. Enugu State is geographically located at coordinates approximately $6^{\circ} 30^{\prime} \mathrm{N}^{\circ} 30^{\prime} \mathrm{E}$ and is made up of 17 Local Government Areas (L. G. As) namely: Aninri, Awgu, Enugu East, Enugu North, Enugu South, Ezeagu, Igbo Etiti, Igbo Eze North, Igbo Eze South, Isi Uzo, Nkanu, Uzouwani East, Nkanu West, Nsukka, Oji River, Udenu and Udi. Enugu South, Enugu North and Enugu East L. G. As made up the Capital Territory (Enugu) of Enugu State while Nsukka town is the Nsukka L. G. A. and it is a University town with a University Veterinary Teaching Hospital. Enugu and Nsukka are geographically located at coordinates approximately 6 6 $27^{\prime} 9.60^{\prime}{ }^{\prime} 7^{\circ} 30^{\prime} 37.20^{\prime \prime} \mathrm{E}$ and 6 51 '24"N7 23 '45"E, respectively. They are the two most populated towns in Enugu State, with population of about 722,664 and 309,633, respectively (NPC, 2007). Majority of veterinarians in Enugu State are practicing in government and/or privately owned clinics in these towns (Enugu and Nsukka). The study population consisted of veterinarians in Enugu State, Southeast Nigeria.

\section{Ethical approval}

Ethical approval was not necessary for this study. However, informed consent from all participants involved in the study was obtained and confidentiality/anonymity of the data obtained was ensured.

\section{Study design and sampling procedure}

This is a quantitative descriptive survey. Between January and March, 2017, a questionnaire based crosssectional study was conducted to assess the perception/level of awareness and practices of ABS amongst veterinarians. Enugu and Nsukka were selected purposively because majority of practicing/teaching veterinarians in Enugu State are based in these towns. The sample size was estimated at 384 participants from the two towns using the method of Thrushfield (1997):

$$
\mathrm{n}=1.96^{2} \times \mathrm{P}_{\exp }\left(1-\mathrm{P}_{\exp }\right) / \mathrm{d}^{2}
$$

Where $\mathrm{n}=$ sample size, Pexp $=$ expected proportion of knowledge about ABS which was assumed to be $50 \%$ and d $=$ desired absolute precision level which was assumed to be $5 \%$. Selection of veterinarians was based on their willingness to participate in the study.
Data collection

Information about the level of awareness and practices of ABS as well as the socio-demographic characteristics of the respondents were collected using a self-administered structured questionnaire. The questionnaire was developed after a literature review of comparable studies (Abbo et al., 2013; Burger et al., 2016; Castro-Sanchez et al., 2016) and validated by a pilot study on 10 veterinarians. Participation was voluntary. Upon the completion of the questionnaire, the interviewer gave the respondents opportunity to ask questions and provided them with relevant $A B R$ and $A B S$ information.

\section{Data analysis}

The data obtained were analyzed using SPSS version 15.0. Chi-square $\left(\chi^{2}\right)$ was used to determine the possible association between variables and the awareness/knowledge and practices of ABS. Values of $P<0.05$ were considered significant. An overall knowledge score was assessed by calculating the total percentage of correct answers for the questions (Abbo et al., 2013; Asekun-Olarinmoye et al., 2014). The data of the pilot study was not used for the final analysis.

\section{Results}

\section{Socio-demographic characteristics of respondents}

A total of 384 participants were sampled from the purposively selected towns in Enugu State. Of these, 365 (95\%) returned a response, but only 280 (75.9\% response rate) responses were sufficiently completed to be analyzed. Of the 280 participants that sufficiently completed their response, majority $(66.1 \%, 185)$ were between the ages of 25 and 40 years old (Table 1$)$. Two hundred and one (71.8\%) of the respondents were males, while $28.2 \%$ were females. One hundred and sixty four (58.6\%) of the respondents were based in Enugu and 116 (41.4\%) were practicing/teaching in Nsukka. Majority of the respondents (68.6\%, 192) had First Degree while 26.4\% (74) had Masters and $5 \%$ (14) were Doctorate degree holders.

\section{Perceptions/Level of knowledge/awareness about ABS}

Of the 280 respondents, only $60(21.4 \%)$ had overall knowledge of ABS, 41 (17.1\%) of the respondents had heard about the concept ABS, while 60 (21.4\%) indicated they know the principles of ABS (Table 1). Using antibiotics only when necessary $(18,6.4 \%)$, administering antibiotics at the appropriate dose $(18,6.4 \%)$ and administering antibiotics for appropriate duration in every case $(12,4.3 \%)$ were the only principles perceived by minority of the respondents as strategies of ABS. The study also showed that age, gender, qualification and location did not exert any influence $(P>$ 0.05 ) on the awareness of respondents about ABS. Regarding the goals of $A B S$, minority of the respondents perceived that $\mathrm{ABS}$ is aimed at increasing the use of broad-spectrum antibiotics $(35.4 \%, 99)$, reducing duration of hospital stay $(13.9 \%, 39)$, minimizing toxicity and other adverse effects $(16.8 \%, 47)$, increasing duration of antibiotic therapy to ensure therapeutic success $(27.1 \%, 76)$ and reducing ABR $(43.2 \%, 121)$. 
Table 1. Socio-demographic characteristics of veterinarians in the study area

\begin{tabular}{|c|c|c|}
\hline Socio-demographic characteristics & Frequency & Percentage (\%) \\
\hline \multicolumn{3}{|l|}{ Age } \\
\hline $25-40$ & 185 & 66.1 \\
\hline $41-56$ & 75 & 26.8 \\
\hline 57 and above & 20 & 7.1 \\
\hline \multicolumn{3}{|l|}{ Sex } \\
\hline Male & 201 & 71.8 \\
\hline Female & 79 & 28.2 \\
\hline \multicolumn{3}{|l|}{ Qualification } \\
\hline First Degree & 192 & 68.6 \\
\hline Masters & 74 & 26.4 \\
\hline Doctorate & 14 & 5 \\
\hline \multicolumn{3}{|l|}{ Years of practice } \\
\hline 1 and below & 18 & 6.4 \\
\hline $2-4$ & 73 & 26.1 \\
\hline 5 and above & 189 & 67.5 \\
\hline \multicolumn{3}{|l|}{ Location } \\
\hline Enugu & 164 & 58.6 \\
\hline Nsukka & 116 & 41.4 \\
\hline
\end{tabular}

Table 2. Perceptions/Level of knowledge possessed by respondents about antibiotic stewardship

\begin{tabular}{ccc}
\hline Perception/level of knowledge & Frequency & Percentage (\%) \\
\hline Overall knowledge of antibiotic stewardship & 60 & 21.4 \\
Heard about antibiotic stewardship & & 17.1 \\
Yes & 48 & 82.9 \\
No & 232 & 21.4 \\
Know the principles of antibiotic stewardship & 60 & 78.6 \\
No & 220 & 6.4 \\
Principles of antibiotic stewardship & & 2.1 \\
Using antibiotics only when necessary & 18 & 6.4 \\
Choosing the appropriate antibiotics & 6 & 4.3 \\
\hline Administering antibiotics at the appropriate dose & 18 & 1.8 \\
\hline Administering antibiotics for appropriate duration in every case & 12 & 2.5 \\
Therapeutic monitoring of antibiotics & 5 & 1.4 \\
Study of antibiotics & 7 & 13.9 \\
Improved hygiene & 4 & 16.8 \\
\hline Antibiotic stewardship goals & 39 & 35.4 \\
\hline Reducing duration of hospital stay & 47 & 27.1 \\
\hline Minimizing toxicity and other adverse effects & 99 & 43.2 \\
\hline Increasing use of broad spectrum antibiotics & 76 & 121 \\
\hline Reducing antibiotic resistance & & \\
\hline
\end{tabular}

Behaviours/attitudes/practices of antibiotic stewardship

With regards to prescribing behaviour, $38.6 \%$ (108) of the respondents prescribe or has prescribed antibiotics without seeing/examining their patient while majority of the respondents $(250,89.3 \%)$ prescribe antibiotics for any case suspected to be infectious (Table 3). Nearly all the respondents $(262,93.6 \%)$ prescribe broad-spectrum antibiotics when bacterial infection is suspected whereas a lower proportion of the respondents $(27.9 \%, 78)$ prescribe narrow-spectrum antibiotics on suspicion of bacterial infection. Majority of the respondents $(87.1 \%, 244)$ prescribe different classes/types of antibiotics to ensure therapeutic efficacy while more than two-third of the respondents $(61.4 \%, 172)$ prescribe/administer antibiotics for prevention/treatment of diseases in a herd/flock. Majority of the respondents $(80 \%, 224)$ prescribe newergeneration antibiotics than older one while nearly half of the respondents $(47.1 \%, 132)$ prescribe overdose of antibiotics to ensure efficacy. Less than one-third (78, 27.9\%) of the respondents adhere strictly to the recommended dose of antibiotics during prescription and less than half of the respondents $(42.9 \%, 120)$ consider whether an infection is self-limiting before prescribing antibiotics. Minority of the respondents consult veterinary 
formulary/other resources when skeptical about a drug's mechanism of action during prescription $(39.3 \%, 110)$ and request for antibiogram of animal isolates within the locality to guide and update on choice of antibiotic for empiric treatment $(1.1 \%, 3)$, while more than one-third $(34.2 \%, 96)$ of the respondents prescribe antibiotics requested by their clients. On microbiological analysis that guides antibiotics prescription, low proportions of the respondents submit samples for bacteriological studies $(27.9 \%, 78)$, isolate infectious agent to prove bacterial involvement before prescribing antibiotics $(19.3 \%, 54)$ and conduct sensitivity test before prescribing antibiotics $(23.6 \%, 66)$, respectively.

Concerning administration of antibiotics to patients, majority of the respondents $(71.4 \%, 200)$ allow their clients to administer antibiotics to their animals at home, change antibiotics when therapeutic failure is perceived following the use of an antibiotic $(93.6 \%, 262)$, encourage/advise clients to buy antibiotics and administer to their animals $(67.9 \%, 190)$ and administer antibiotics to their patients without determining their body weight properly (69.3\%, 194). Majority of respondents also ensure that antibiotics are administered to patients for the appropriate duration $(91.4 \%, 256)$ and adhere to the recommended route when giving antibiotics to their patients $(89.3 \%, 250)$. A low proportion of the respondents, considers whether an antibiotic is of substandard quality before acquisition for use in treating animals $(11.1 \%, 31)$ and uses antibiotics for a prolonged duration $(17.1 \%, 48)$, while $41.9 \%$ (117) of the respondents wash their hands always and properly with disinfectants after handling/examining a patient

Regarding education of clients and role of veterinarians in ABS programs, majority of the respondents $(68.2 \%, 191)$ educate their clients on the need for vaccinating their animals against preventable diseases and almost all $(97.1 \%$, 270) of them agreed that veterinarians have major role to play in ensuring proper antibiotic use. Minority of the respondents educate their clients on appropriate use of antibiotics $(32.5 \%, 91)$ whereas majority of the respondents $(67.9 \%, 190)$ admit animals in their clinics for long duration. There was no significant association $(P>0.05)$ between the sex, age, qualification and location and practices of ABS. More than half of the respondents (53.9\%, 151) perceived that antibiotics are overused by veterinarians nationally, all the respondents $(100 \%, 280)$ agreed that strong knowledge of antibiotics is important in their veterinary career while nearly all $(97.1 \%, 270)$ agreed that veterinarians have a role to play in ensuring proper use of antibiotics.

Table 3. Level of practices of antibiotic stewardship by veterinarians in the study area

\begin{tabular}{|c|c|c|}
\hline Practices, Behaviours and Attitudes & Frequency & Percentage (\%) \\
\hline Prescribe or have prescribed antibiotics without seeing/examining the animal & 108 & 38.6 \\
\hline Prescribe antibiotics for any case suspected to be infectious & 250 & 89.3 \\
\hline Submit samples for microbiological analysis before prescribing/administering antibiotics & 78 & 27.9 \\
\hline Isolate infectious agent to prove bacterial involvement before prescribing antibiotics & 54 & 19.3 \\
\hline Conduct antibiotic sensitivity testing before prescription of antibiotics & 66 & 23.6 \\
\hline Allow clients to administer antibiotics to their animals at home & 200 & 71.4 \\
\hline Encourage/advise clients to buy antibiotics and administer to their animals & 190 & 67.9 \\
\hline Ensure that antibiotics are administered to patients for appropriate duration & 256 & 91.4 \\
\hline Change antibiotics when therapeutic failure is perceived following the use of an antibiotic & 262 & 93.6 \\
\hline Prescribe broad-spectrum antibiotics when bacterial infection is suspected & 262 & 93.6 \\
\hline Prescribe narrow-spectrum antibiotics when bacterial infection is suspected & 78 & 27.9 \\
\hline Adhere to recommended dose when prescribing/administering antibiotics for/to patients & 78 & 27.9 \\
\hline Prescribe/administer of overdose of antibiotic to patients to ensure therapeutic success & 132 & 47.1 \\
\hline Combine antibiotics to ensure therapeutic success & 244 & 87.1 \\
\hline Prescribe antibiotic on request of the client & 96 & 34.2 \\
\hline Prescribe antibiotics for prophylactic/metaphylactic treatment of animals in a herd/flock & 172 & 61.4 \\
\hline Administer antibiotics to animals without determining their body weight properly & 194 & 69.3 \\
\hline Admits animals in the hospital for long duration & 190 & 67.9 \\
\hline Prolong usage of an antibiotic & 48 & 17.1 \\
\hline Consider whether an infection is self-limiting before prescribing antibiotics & 120 & 42.9 \\
\hline $\begin{array}{l}\text { Choosing new generation antibiotics (e.g., extended-spectrum) as first line of treatment rather than older } \\
\text { generations like penicillin }\end{array}$ & 224 & 80 \\
\hline Adhere to the recommended route of administration when giving antibiotics to patients & 250 & 89.3 \\
\hline Consult veterinary formulary/other educational resources when in doubt of a drug's mechanism of action & 110 & 39.3 \\
\hline Washing of hands always and properly with disinfectants after handling/examining an animal & 117 & 41.9 \\
\hline Consider whether an antibiotic is of substandard quality before acquisition for use in treating animals & 31 & 11.1 \\
\hline Strong knowledge of antibiotic is helpful in my Veterinary career & 280 & 100 \\
\hline $\begin{array}{l}\text { Request for antibiogram of animal isolates within the locality to guide and update on choice of antibiotic } \\
\qquad \text { for empiric treatment }\end{array}$ & 3 & 1.1 \\
\hline Educate clients to vaccinate their animals against preventable diseases & 191 & 68.2 \\
\hline $\begin{array}{l}\text { Educate clients on appropriate use of antibiotics, adherence to withdrawal periods and resistance-related } \\
\qquad \text { issues }\end{array}$ & 91 & 32.5 \\
\hline Veterinarians have a major role to play in ensuring proper use of antibiotics & 272 & 97.1 \\
\hline Antibiotics are overused by veterinarians nationally & 151 & 53.9 \\
\hline
\end{tabular}




\section{Discussion}

The health and economic impact of ABR is enormous and dreadful, thus, veterinarians (as key healthcare providers) have been encouraged to hold the responsibility of ABS (principally targeted to reduce antibiotic use and development/spread of ABR) in practice area (Erku, 2016; Khan et al., 2016). The results obtained from this study have demonstrated that the overall level of awareness or knowledge about ABS amongst veterinarians in the study area is very poor $(21.4 \%)$. This could be attributed to the fact that very few $(17.1 \%)$ of the respondents in this study, had heard about ABS. Cotta et al. (2014) reported that $41 \%$ have heard of antimicrobial stewardship (AMS) among practitioners (physicians, surgeons, pharmacists, anaesthetists, nurses) in a large private hospital in Australia while Burger et al. (2016) reported that $83.5 \%$ have heard about AMS among final year pharmacy students in 3 South African universities. The differences in proportions of respondents that have heard of AMS in these studies, may be due to disparity in the level of AMS awareness education that has been conducted in the healthcare facilities/study area, awareness obtained from other sources (such as mass media, journals, etc.) and/or level of exposure to AMS in educational institutions, in the various study areas. Thus, the finding of very low proportion of respondents that have heard of ABS in this study, suggested there is little or no AMS education awareness (via mass media, in schools, social centres, etc) in the study area (Abbo et al., 2013; Lee et al., 2015).

Lack of association between ages, sex, qualification and location and awareness of respondents in this study about $\mathrm{ABS}$, may be because all the respondents were similarly not exposed to the concept of ABS during Veterinary school. It equally suggested that there is no ASP in form of continuing education, conferences, seminars, symposia, etc. (Lee et al., 2015) organized for veterinarians in the study area. It also suggested that curricula in Nigerian Veterinary schools are deficient on issues of ABR and ABS. Therefore, the few respondents in this study that exhibited awareness of ABS, may likely be those specialized/specializing in Microbiology, Public Health or Pharmacology and/or those that could have heard of ABS through other means/from various sources (Cotta et al., 2014; Asekun-Olarinmoye et al., 2014). Cisneros et al. (2014) noted that antibiotic misuse is likely to be due to the scarce training offered in this respect to the practicing clinician.

Poor knowledge about ABS may underline the wrong perceptions about the principles of ABS exhibited among majority of the respondents in this study. It is worrisome that minority of the respondents in this study rightly perceived/knew that using antibiotics only when necessary (6.4\%), administering antibiotics at the appropriate dose (6.4\%) and administering antibiotics for appropriate duration in every case $(4.3 \%)$ are among the core principles/strategies of $\mathrm{ABS}$. These results are lower than the findings of Burger $e t$ al. (2016). It has been reported that apart from monitoring the antibiotic prescribing practice, continuous supervision of antibiotic dispensing practice and improving hygiene is a key approach to hold ABR (Cotta et al., 2014; Erku, 2016). Unfortunately, nearly all the respondents in the current study do not know that therapeutic monitoring of antibiotic, study of antibiotics and improved hygiene were also strategies of ABS (Abbo et al., 2013; Roca et al., 2015). The major key factor in the repression of $\mathrm{ABR}$ is reduction of disproportionate antibiotic utilization and this could be accomplished to a great extent by modification of prescribing manners of the clinicians/veterinarians (Dryden et al., 2011; Al-Harthi et al., 2013; Al-Harthi et al., 2015). Reduction in antibiotic use in veterinary settings could be achieved by improved personal hygiene by the veterinarians, animal handlers / caretakers and improved environmental sanitation (biosecurity) in the farm (Coyne et al., 2016: Rhouma et al., 2016). The audit and feedback strategy of ABS has been reported to be the most effective way of monitoring antibiotic usage (Chung et al., 2015).

Among the goals of ABS asked in the questionnaires, only reduction of $\mathrm{ABR}$ was rightly perceived by nearly half of the respondents in this work. This finding is lower than the result (52.7\%) of Khan et al. (2016) among community pharmacists in Malaysia. It is very disturbing that more than one-third (35.4\%) of the respondents perceived that ABS is aimed at increasing the use of broad-spectrum antibiotics. This finding contrasts the result (7.7\%) of Burger et al. (2016). It is also of concern that although in the minority, some respondents $(27.1 \%)$ in this study, felt that ABS aims at increasing duration of antibiotic therapy to ensure therapeutic success. This finding is also higher than that (10.4\%) of Burger et al. (2016). Two-third of the respondents in this study agreed that they prescribe antibiotics for prophylaxis/metaphylaxis for animals in a herd/flock. Although it is still controversial on how the use of antibiotics for prophylaxis/metaphylaxis cause ABR (Bengston and Greko, 2014), an important principle of ABS is avoiding selection pressure in the patient, both on pathogen and commensal by avoiding unnecessary use, choosing the least broad-spectrum antibiotic, adequate doses, a good timing and the shortest possible duration (Pulicini and Gyssens, 2013).

Perceptions and attitudes could affect how prescribers interpret the consequences of antibiotic use and the variability in antibiotic prescribing that is seen in veterinary clinical practice (Abbo et al., 2013). Thus, wrong perception of most respondents in this study about ABS, may be why a high proportion of them are engaging in inappropriate practices that are untoward ABS such as prescribing antibiotics without seeing/examining their patient, changing antibiotics when therapeutic failure is perceived following the use of an antibiotic, and prescribing/administering overdose of antibiotic to patients to ensure therapeutic efficacy. Overuse of antibiotic may result from the clinician intention to fulfill the responsibility of offering optimal therapy for the individual patient under his/her care while overlooking the responsibility of preserving the efficacy of antibiotics and minimizing the development of resistance in the same patient and other patients in the future and to public health (Pulicini and Gyssens, 2013; Scaioli et al., 2015). Widespread and overuse of antibiotics, use of broadspectrum antibiotics when narrow spectrum is available are among the leading causes of ABR (Pulcini et al., 2011; 
Navarro-San Francisco et al., 2013; Abera et al., 2014; Burger et al., 2016). In ABS, clinicians are encouraged that where it is imperative to start effective broad-spectrum therapy quickly, subsequent daily review of these prescriptions, and de-escalation to narrow-spectrum antibiotics where possible, should be done (Wickens et al., 2013).

More than one-third (34.3\%) of the respondents in this study prescribe antibiotics on request of the client. AlHarthi et al. (2015) recorded a similar finding among general physicians in Saudi Arabia. It has been suggested that clinicians are usually under pressure from their clients/patients who expect to be prescribed antibiotics, even when they are inappropriate and unlikely to be effective (Coyne et al., 2016; Donald, 2016). Therefore, antibiotic prescribing decisions of veterinarians should be after consideration of intrinsic and extrinsic factors (e.g. type of husbandry practice in food-producing animals) (De Bryine et al. 2013; Coyne et al., 2014; Speksnijder et al., 2015; Coyne et al., 2016). Even more concerning is that majority of the respondents in this study choose new generation antibiotics (e.g., extended-spectrum antibiotics) as first line of treatment. In a study conducted by Busani $e t$ al. (2006) among veterinarians in Italy, therapeutic failure was reported as the main cause of the use of newer antibiotics. Lack of policy guiding antibiotic use in Nigeria may be why respondents in the study area engage in this imprudent practice. Fluoroquinolones, extended-spectrum $\beta$-lactams ( $3^{\text {rd }}-$ and $4^{\text {th }}$-generation cephalosporins) and macrolides, are classified as critically important antimicrobials of the highest priority for risk management in their use, to maintain efficacy for human use (WHO, 2011; Coyne et al., 2016); therefore, there is need for educating veterinarians in Nigeria concerning the use of these critically-important drugs in animals.

It is worrying that a minority of the respondents in the hereby study felt that reducing duration of hospital stay (13.9\%) and minimizing toxicity and other adverse effects $(16.8 \%)$, are also goals of ABS. This may possibly underline why majority of these respondents admit their patients for a long time in their clinics and some others use an antibiotic for prolonged duration (17.1\%). In South Africa, Burger $e t$ al. (2016) recorded $83.1 \%$ who knew that ABS is aimed at minimizing toxicity and other adverse effects in patients, among final year pharmacy students. ABS is the practice of escalating and sustaining the rational/judicious use of antibiotics to optimize patient outcomes, reduce costs, and avoid the collateral side effects (such as the generation of resistant organisms and untoward effects in the individual patient) linked with these medications (Struelens, 2003; Wickens et al., 2013; Burger et al., 2016; Erku, 2016).

In the current study, almost none of the respondents request for antibiogram of animal isolates within the locality to guide the choice of antibiotics in empiric treatment of bacterial infection and a minority of the respondents (23.6\%) conduct antibiotic sensitivity test before prescribing antibiotics. Determination of antibiogram of isolates is crucial for guiding the choice of antibiotic therapy (Guardabassi and Prescott, 2015; Coyne et al., 2016). A more timely antibiotic sensitivity testing has been recognized as the best tool for combating $A B R$ in clinically- relevant bacteria (Di Briyne et al., 2013; Dunne and Belkum, 2014). Thus, it is a matter of urgency that Nigerian veterinarians should be educated on $A B S$ because antibiotic therapy not guided by antibiogram is the major cause of emergence and spread of multidrug-resistant organisms (Guardabassi and Prescott, 2015). In addition, majority of the respondents $(89.3 \%)$ prescribe antibiotics for any case suspected to be infectious. This blind antibiotics prescription/therapy increases the spread of ABR and could be attributed to lack of affordable test kits and high cost of laboratory analysis in Nigeria (Sosa et al., 2014). Diagnosis has been recognized as an essential tool to contain ABR (Okeke et al., 2011). Collaboration with Microbiology laboratory has been identified as one of the requirements for establishment of ASP and to achieve ABS (Guardabassi and Prescott, 2015; Coyne et al., 2016). This practice of prescribing antibiotics without conducting laboratory tests by majority of the respondents in the study portends grave danger if continued, because the rate of development of $A B R$ in veterinary settings in the country could become unprecedented and uncontainable. Veterinarians, animal handlers/caretakers and the public are at risk of acquiring resistant organisms from animals (via contact and food chain) and veterinary environment (Coyne et al., 2016). The most important interventions to combat $A B R$ are considered to be education on antibiotic therapy, development of antibiotic usage policies and the development of institutional guidelines for antibiotic use (Cotta et al., 2014; Lee et al., 2015; Burger et al., 2016). Therefore, it is crucial that ASPs that involve evidencebased guidelines, educational programmes and regular feedback of antibiotic usage data to veterinarians to promote rationale-based and evidence-based prescribing, be developed and established in Nigeria (Wickens et al., 2013; Burger et al., 2016). Increasing awareness of national ABR patterns and knowledge of latest treatment guidelines, are the important strategies that could be implemented as a part of veterinary ABS in the study area (Khan et al., 2016).

The use of eco-friendly alternatives, such as vaccines, to prevent diseases thereby minimizing antibiotic use has been suggested to be one of the effective ways of containing $A B R$ (Cabello et al., 2016; Coyne et al., 2016). In ASPs, veterinarians are supposed to be in the lead in educating clients to vaccinate their animals against preventable diseases. In the current study, more than two-third of the respondents (68.2\%) advises their clients on the need for routine vaccinations. Studies have shown that minimal use of antibiotics (achievable by vaccinating against preventable diseases) by clinicians, could be a strategy for containing ABR (Llor and Bjerrum, 2014).

The use of substandard drugs has been reported as a major cause of $\mathrm{ABR}$, especially in developing countries, where there are no regulations guiding the marketing and usage of antibiotics (Okeke et al., 1999; Laxminarayan et al., 2013; Burger et al., 2016). It is therefore a matter of serious concern, that minority of the respondents in this study, considers whether an antibiotic is of substandard quality before acquiring it for use in their patients. Pressure from the clients to prescribe affordable antibiotics may also account for low proportions of respondents in this study that check antibiotic quality before usage (Coyne et al., 
328

2016). Maximization of profit, availability, affordability on the part of the veterinarian, and/or ignorance, may also be reasons why majority of respondents in this study neglect drug quality (Okeke et al., 1999; Isturiz and Carbon, 2000; Coyne et al., 2016). Veterinarians' ability to profit from the sale of antibiotics has been highlighted as a potential conflict of interest in ABS (Rollin, 2006; WHO, 2001; Coyne et al., 2016). In Nigeria, high medicine prices are an important public health concern. Since the prices of drugs, including antibiotics, are not regulated in Nigeria, they vary considerably from one veterinary clinic/shop to another. Decoupling antibiotic sales to eliminate the potential that profit may drive prescribing behaviours among veterinarians have been suggested (Coyne $e t$ al., 2016). Moreover, there is no recognized ASP executed in veterinary clinics in Nigeria. This calls for the establishment of ASPs backed by strictly enforced policies regarding the sales and usage of antibiotics in Nigeria.

In this study, majority of the respondents ensures that their patients are given the prescribed antibiotics for the appropriate duration. This practice should be encouraged because poor patient adherence to prescribed antibiotics is the major untoward $\mathrm{ABS}$ attitude resulting in $\mathrm{ABR}$ (Pulcini et al., 2011; Navarro-San Francisco et al., 2013; Abera et al., 2014; Burger et al., 2016). Clients/patients' wrong habits and their lack of knowledge is also a leading cause for $A B R$ (Scaioli et al., 2015; Coyne et al., 2016). The WHO urged member countries to initiate educational interventions for the general population aimed at rationalizing the use of antibiotics to combat resistance (WHO, 2001; Awad and Aboud, 2015). Veterinarians as major healthcare providers are expected to be educators of their clients/the public on the appropriate use of antibiotics and issues of $A B R$ (Belognia and Schwartz, 1998; Lee et al., 2015; Erku, 2016). More than one-third (35.9\%) of the respondents in this study, educates their clients on the appropriate use of antibiotics, adherence to withdrawal period and issues of $\mathrm{ABS}$ and $\mathrm{ABR}$. This result is higher than the findings (24.2\%) of Erku et al. (2016) among community pharmacists in Ethiopia. But it is lower than $61.2 \%$ who often educate their patients on issues of ABS and resistancerelated issue amongst community pharmacists in Malaysia (Khan et al., 2016). Improving the clients/public knowledge and changing their attitudes towards antibiotic use, is a crucial strategy to maintain antibiotic effectiveness (Awad and Aboud, 2015). Variations in results of these studies could be related to differences in awareness about the principles of ABS, the extent to which ASP is established and the level of engagement of the various healthcare practitioners in the study areas. Low involvement of veterinarians in education of clients in this study could be related to lack of awareness about ABS and their role in ASPs.

Interestingly, more than half (53.9\%) of the respondents in the present study, perceived that antibiotics are overused by veterinarians nationally. This finding is consistent with that of Abbo et al. (2013) among $4^{\text {th }}$-year medical students in 3 medical schools in America. Overuse of antibiotics by veterinarians in Nigeria, may be attributed to the poor knowledge about antibiotics and ABS, thus, antibiotics would be over-prescribed and disproportionately used. However, all the respondents in this study perceived that strong knowledge of antibiotics is crucial for their veterinary career and nearly all agreed that veterinarians have a major role to play in ensuring proper antibiotic use. This finding is similar to that of Erku (2016) in Ethiopia. Veterinarians are in position to coordinate $\mathrm{ABS}$ in veterinary clinics; therefore, they should have strong interest in and good knowledge of ABR and therapy (Guardabassi and Prescott, 2015). By taking advantage of the mostly optimistic views of the respondents in this study, on their role as veterinarians in ASPs, the Federal Ministry of Health, Veterinary Council of Nigeria, Veterinary hospital administrations, and other stakeholders, should provide strategies on how they could take action as ABS proponents (Erku, 2016).

Strengths of this study were that it highlighted an area where the availability of literature is limited. A high response rate was obtained and the survey was anonymous and voluntary, this likely reduced the tendency of the respondents to provide "socially desired" answers (Abbo et al., 2013; Burger et al., 2016). In addition, the study population is the practicing/teaching veterinarians, thus providing a better estimate of their Veterinary education after graduation. However, the results may not be generalized to all veterinarians in Nigeria since only Enugu State was sampled. Moreover, since the participants were approached randomly to collect data, they may not account for the differences within the population. Therefore, caution should be taken while interpreting these results in the context of potential identified limitations (Khan et al., 2016). Despite the identified limitations, the findings of this study could be useful for optimizing the use of antibiotics in veterinary settings in Nigeria.

\section{Conclusions}

The overall perception/level of awareness about ABS among veterinarians in Enugu State, Southeastern Nigeria is abysmally poor. This is attributed to lack of education/training on ABS and absence of established ASPs in the country. Consequently, veterinarians in the study area hugely engaging in inappropriate practices that are untoward $A B S$, thereby increasing the problem of $A B R$. Thus, there is urgent need for intensified education of veterinarians in Nigeria on $A B S$ and the teaching of the principles and practices of ABS should begin during Veterinary school.

\section{References}

Abera B, Kibret M, Mulu W (2014). Knowledge and beliefs on antimicrobial resistance among physicians and nurses in hospitals in Amhara region, Ethiopia. BMC Pharmacology and Toxicology 15(1):26.

Al-Harthi SE, Khan LM, Osman A-MM, Alim MA, Saadah OI, Almohammadi AA, Khan FM, Kamel FO (2015). Perceptions and knowledge regarding antimicrobial stewardship among clinicians in Jeddah, Saudi Arabia. Saudi Medical Journal 36(7):813-820.

Al-Harthi SE, Khan LM, Abed HH, Alkreathy HM, Ali AS (2013). Appraisal of antimicrobial prescribing practices of governmental and non-governmental dentists for hospitals in the western region of Saudi Arabia. Saudi Medical Journal 34:1262-1269. 
Asekun-Olarinmoye EO, Akinwusi PO, Adebimpe WO, Omisore AG, Isawumi MA, Hassan MB, et al. (2014). Perceptions and use of antimicrobials among staff of a university community in Southwestern Nigeria. SAGE Open 4(2) doi:10.1177/ 2158244014529778.

Awad AI, Aboud EA (2015). Knowledge, attitude and practice towards antibiotic use among the public in Kuwait. PLoS ONE 10(2): e0117910. doi:10.1371/journal.pone.0117910.

Bartlett JG (2011). A call to arms: the imperative for antimicrobial stewardship. Clinical Infectious Diseases 5(suppl 1):S4-S7.

Belongia EA, Schwartz B (1998). Strategies for promoting judicious use of antibiotics by doctors and patients. British Medical Journal 317(7159):668-671.

Bengtsson B, Greko C (2014). Antibiotic resistance - consequences for animal health, welfare, and food production. Upsala Journal of Medical Sciences 119(2):96-102.

Bowater L (2015). Antimicrobial stewardship: the role of scientists? Journal of Antimicrobial Chemotherapy 70:1925-1927.

Burger M, Fouriea J, Lootsa D, Mnisia T, Schellacka N, Bezuidenhouta S, Meyera JC (2016). Knowledge and perceptions of antimicrobial stewardship concepts among final year pharmacy students in pharmacy schools across South Africa. Southern African Journal of Infectious Diseases 31(3):84-90.

Busani L, Graziani C, Binkin N, Franco A, Di Egidio A, Battisti A (2004). Survey of knowledge, attitudes and practice of Italian beef and dairy cattle veterinarians concerning the use of antibiotics. Veterinary Record 155:733-738.

Cabello FC, Godfrey HP, Buschmann AH, Dölz HJ (2016). Aquaculture as yet another environmental gateway to the development and globalisation of antimicrobial resistance. Lancet Infectious Diseases 16(7):e127-133.

Castro-Sánchez E, Drumright LN, Gharbi M, Farrell S, Holmes AH (2016). Mapping antimicrobial stewardship in Undergraduate Medical, Dental, Pharmacy, Nursing and Veterinary education in the United Kingdom. PLoS ONE 11(2):e0150056. doi:10.1371 /journal.pone.0150056.

Cattaneo AA, Wilson R, Doohan D, LeJeune JT (2009). Bovine veterinarians' knowledge, beliefs, and practices regarding antibiotic resistance on Ohio dairy farms. Journal of Dairy Science 92:3494 3502.

Chambers HF (2006). General principles of antimicrobial therapy. In: Brunton L, Parker K, Blumenthal D, Buxton I (Eds). Goodman and Gilman's. The Pharmacological basis of therapeutics, 11th ed. New York, USA, Mc Graw Hill pp 1095-1100.

Chung GW, Wu JE, Yeo CL, Chan D, Hsu LY (2013). Antimicrobial stewardship: a review of prospective audit and feedback systems and an objective evaluation of outcomes. Virulence 4:151-157.

Cisneros JM, Neth O, Gil-Navarro MV, Lepe JA, Jimenez-Parrilla F, Cordero E, ... Molina J (2014). Global impact of an educational antimicrobial stewardship programme on prescribing practice in a tertiary hospital centre. Clinical Microbiology and Infection 20:8288.

Cosgrove $S$ (2006). The relationship between antimicrobial resistance and patient outcomes: mortality, length of hospital stay, and health care costs. Clinical Infectious Diseases 42:S82-S89.

Cotta MO, Robertson MS, Tacey M, Marshall C, Thursky KA, Liew D (2014). Attitudes towards antimicrobial stewardship: results from a large private hospital in Australia. Healthcare Infection 19(3):89-94.

Coyne LA, Pinchbeck GL, Williams NJ, Smith RF, Dawson S, Pearson RB (2014). Understanding antimicrobial use and prescribing behaviours by pig veterinary surgeons and farmers: a qualitative study. Veterinary Record 175(23):593.

Coyne LA, Latham SM, Williams NJ, Dawson S, Donald IJ, Pearson RB, ... Pinchbeck GL (2016). Understanding the culture of antimicrobial prescribing in agriculture: a qualitative study of UK pig veterinary surgeons. Journal of Antimicrobial Chemotherapy 71:3300-3312

Dellit TH, Owens RC, McGowan JE Jr, Gerding DN, Weinstein RA, Burke JP, Huskins WC, et al. (2007). Infectious Diseases Society of America and the Society for Healthcare Epidemiology of America guidelines for developing an institutional program to enhance antimicrobial stewardship. Clinical Infectious Diseases 15:44.

De Briyne N, Atkinson J, Borriello SP, Price S (2013). Factors influencing antibiotic prescribing habits and use of sensitivity testing amongst veterinarians in Europe. Veterinary Record 173:475.

Donald I (2016). Antimicrobial Resistance and Psychology: Research Brief. ESRC AMR Research Champion/University of Bristol.

Dryden M, Johnson AP, Ashiru-Oredope D, Sharland M (2011). Using antibiotics responsibly: right drug, right time, right dose, right duration. Journal of Antimicrobial Chemotherapy 66:2441-2443.

Dunne JWM, van Belkum A (2014). More timely antimicrobial susceptibility testing as a tool in combatting antimicrobial resistance in clinically relevant microorganisms: is there more than one way to skin a cat? Clinical Microbiology Newsletter 36:149-153.

Erku DA (2016). Antimicrobial stewardship: a cross-sectional survey assessing the perceptions and practices of community pharmacists in Ethiopia. Interdisciplinary Perspectives on Infectious Diseases http://dx.doi.org/10.1155/2016/5686752.

File Jr TM, Srinivasan A, BartlettJG (2014). Antimicrobial stewardship: importance for patient and public health. Clinical and Infectious Diseases 59(S3):S93-96.

Fitchett JR, Atun R (2016). Antimicrobial resistance: Opportunity for Europe to establish global leadership. Lancet Infectious Diseases 16:388-389.

Grigoryan L, Burgerhof JG, Haaijer-Ruskamp FM, Degener JE, Deschepper R, Monnet DL, ... Birkin J (2007). Is self-medication with antibiotics in Europe driven by prescribed use? Journal of Antimicrobial Chemotherapy 59:152-156.

Guardabassi L, Prescott JF (2015). Antimicrobial stewardship in small animal veterinary practice: from theory to practice. Veterinary Clinics of North America: Small Animal Practice 45:361-376.

Huttner A, Harbarth S, Carlet J, Cosgrove S, Goossens H, Holmes A, ... Pittet D (2013). Antimicrobial resistance: A global view from the 2013 World Healthcare - Associated Infections Forum. Antimicrobial Resistance and Infection Control 2:31. 
330

Huynh BT, Padget M, Garin B, Herindrainy P, KermorvantDuchemin E, Watier L, ... Delarocque-Astagneau E (2015). Burden of bacterial resistance among neonatal infections in low income countries: How convincing is the epidemiological evidence? BMC Infectious Diseases 15:127.

Isturiz RE, Carbon C (2000). Antibiotic use in developing countries. Infection Control and Hospital Epidemiology 21(6):394-397.

Khan MU, Hassali MAA, Ahmad A, Elkalmi RM,Zaidi STR, Dhingra $S$ (2016). Perceptions andpractices of community pharmacists towards Antimicrobial stewardship in the state of Selangor, Malaysia. PLoS ONE 11(2): e0149623.

Köck R, Kreienbrock L, van Duijkeren E, Schwarz S (2016). Antimicrobial resistance at the interface of human and veterinary medicine. Veterinary Microbiology 200:1-5.

Landers TF, Cohen B, Wittum TE, Larson EL (2012). A review of antibiotic use in food animals: perspective, policy, and potential. Public Health Reports 127(1):4-22.

Laxminarayan R, Duse A, Wattal A, Zaidi AKM, Wertheim HFL, Sumpradit N, et al. (2013). Antibiotic resistance - the need for global solution. Lancet Infectious Diseases 13(12):1057-1098.

Lee C.-R, Lee JH, Kang L-W, Jeong BC, Lee SH (2015). Educational effectiveness, target, and content for prudent antibiotic use. BioMed Research International http://dx.doi.org/10.1155/2015/214021

Leonard CT, Ward D, Longson C (2017). Antimicrobial resistance: a light at the end of the tunnel? Lancet Infectious Diseases, 389(10071):803.

Levy SB (2002). The 2000 Garrod Lecture: Factors impacting on the problem of antibiotic resistance. Journal of Antimicrobial Chemotherapy 49:25-30.

Llor C, Bjerrum L (2014). Antimicrobial resistance: risk associated with antibiotic overuse and initiatives to reduce the problem. Therapeutic Advances and Drug Safety 5(6):229-241.

Moody J, Cosgrove SE, Olmsted R, Septimus E, Aureden K, Oriola S, ... Trivedi KK (2012) Antimicrobial stewardship:a collaborative partnership between infection preventionists and healthcare epidemiologists. Infection Control \& Hospital Epidemiology, 33(4):328-330.

Navarro-San Francisco C, Del Toro MD, Cobo J, De Gea-García JH, Vañó-Galván S, Moreno-Ramos F, Rodríguez-Baño J, Paño-Pardo JR (2013). Knowledge and perceptions of junior and senior Spanish resident doctors about antibiotic use and resistance: results of a multicenter survey. Enfermedades Infecciosas y Microbiología Clínica 31(4):199-204.

Nigerian Population Commission. Federal Republic of Nigeria (NPC/FRN) (2007). Special FRN, Gazette no 23 on the 2006 population census.

O’Neill J (2014). Antimicrobial resistance: tackling a crisis for the health and wealth of nations. Review on antimicrobial resistance. http://amr-review.org/Publications.

Okeke IN, Lamikanra A, Edelman R (1999). Socioeconomic and behavioral factors leading to acquired bacterial resistance to antibiotics in developing countries. Emerging and Infectious Diseases 5:18-27.
Okeke IN, Peeling RW, Goossens H, Auckenthaler R, Olmsted SS, de Lavison JF, ... Nordqvist K (2011). Diagnostics as essential tools for containing antibacterial resistance. Drug Resistance Updates 14:95106.

Piddock LJ (2016). Reflecting on the final report of the O'Neill review on antimicrobial resistance. Lancet Infectious Diseases 16:767-768.

Pulicini C, Gyssens IC (2013). How to educate prescribers in antimicrobial stewardship practices. Virulence 4(2):192-202.

Pulcini C, Williams F, Molinari N, Davey P,Nathwani D (2011). Junior doctors' knowledge and perceptions of antibiotic resistance and prescribing: a survey in France and Scotland. Clinical Microbiology and Infection 17:80-87.

Roca I, Akova M, Baquero F, Carlet J, Cavaleri M, Coenen S, et al. (2015). The global threat of antimicrobial resistance: science for intervention. New Microbes and New Infection 6:22-29.

Rollin BE (2006). An introduction to veterinary medical ethics: Theory and Cases, 2nd ed. Blackwell Publishing.

Scaioli G, Gualano MR, Gili R, Masucci S, Bert F, Siliquini R (2015). Antibiotic use: a cross-sectional survey assessing the knowledge, attitudes and practices amongst students of a school of medicine in Italy. PLoS ONE 10(4): e0122476.

Sosa AD, Amábile-Cuevas CF, Byarugaba DK, Hsueh PR, Kariuki S, Okeke IN (2010). Antimicrobial resistance in developing countries. New York: Springer.

Spellberg B, Guidos R, Gilbert D, Bradley J, Boucher HW, Scheld WM, ... \& Infectious Diseases Society of America (2008). The epidemic of antibiotic resistant infections: a call to action for the medical community from the Infectious Diseases Society of America. Clinical Infectious Diseases 46:155-164.

Speksnijder DC, Jaarsma ADC, van der Gugten AC, Verheij TJ, Wagenaar JA (2015). Determinants associated with veterinary antimicrobial prescribing in farm animals in the Netherlands: a qualitative study. Zoonoses Public Health 62:39-51.

Srinivasan A (2011). Engaging hospitalists in antimicrobial stewardship: the CDC perspective. Journal of Hospital Medicine 6(suppl 1):S31-S33.

Struelens MJ (2003). Multidisciplinary antimicrobial management teams: the way forward to control antimicrobial resistance in hospitals. Current Opinion in Infectious Diseases 16(4):305-307.

Taylor J, Hafner M, Yerushalmi E, Smith R, Bellasio J, Vardavas R, et al. (2014). Estimating the economic costs of antimicrobial resistance: model and results. Retrieved 24 March 2017 from http://www.rand.org/randeurope/research/projects/antimicrobialresistance-costs.html 2015.

Thrusfield M (1997). Veterinary Epidemiology. Butterworths Publishers, 2nd ed, London.

van Duijkeren E, Greko C, Pringle M, Baptiste KE, Catry B, Jukes H, ... Ružauskas M (2014). Pleuromutilins: use in food producing animals in the European Union, development of resistance and impact on human and animal health. Journal of Antimicrobial Chemotherapy 69:2022-2031.

Viale P, Giannella M, Bartoletti M, Tedeschi S, Lewis R (2015). Considerations about antimicrobial stewardship in settings with 
epidemic extended-spectrum $\quad \beta$-lactamase-producing or carbapenem-resistant enterobacteriaceae. Infectious Diseases and Therapy 4:65-83.

Vickers H (2011). International antibiotic resistance crisis. Better training needed to maintain therapeutic arsenal. Student BMJ 19:d3207.

Wickens HJ, Farrell S, Ashiru-Oredope DAI, Jacklin A, Holmes A, in collaboration with the Antimicrobial Stewardship Group of the Department of Health Advisory Committee on Antimicrobial Resistance and Health Care Associated Infections (ASG-ARHAI) (2013). The increasing role of pharmacists in antimicrobial stewardship in English hospitals. Journal of Antimicrobial Chemotherapy 68:2675-2681.

World Health Organization (WHO) (2001). Global strategy for containment of antimicrobial resistance. Retrieved 17 Nov 2016 from WHO/CDS/CSR/DRS/2001.2.http://www.who.int/csr/ resources/publications/drugresist/en/EGlobal_Strat.pdf.
World Health Organiztion (WHO) (2011). Critically important antimicrobials for human medicine 3rd Revision. WHO, Geneva, Switzerland pp32.

World Health Organization (WHO) (2012). The evolving threat of antimicrobial resistance. Options for action. Geneva: World Health Organization, 2012. Retrieved 17 Nov 2016 from http:// whqlibdoc.who.int/ publications /2012/9789241503181_eng.pdf.

World Health Organization (WHO) (2014). Antimicrobial Resistance. Global Report on Surveillance. Geneva: World Health Organization. Retrieved 17 Nov 2016 from http://apps.who.int/ iris/bitstream/10665/112642/1/9789241564748_eng.pdf.

Zaidi AK, Awasthi S, deSilva HJ (2004). Burden of infectious diseases in South Asia. BMJ 328:811-815. 